\title{
CARACTERIZAÇÃO FENÓLICA DAS UVAS 'ALICANTE' E 'SYRAH' CULTIVADAS EM SAFRA FORA DE ÉPOCA'
}

\author{
ALESSANDRO JEFFERSON SATO ${ }^{2}$, CASSIA INÊS LOURENZI FRANCO ROSA ${ }^{3}$,

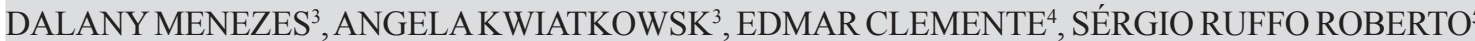

RESUMO - O objetivo do trabalho foi caracterizar a evolução da maturação fenólica das videiras 'Alicante' e 'Syrah' (Vitis vinifera L.) cultivadas fora de época. A área experimental foi instalada em uma propriedade pertencente à Vinícola Intervin ${ }^{\circledR}$, localizada em Maringá-PR. Os vinhedos foram estabelecidos em julho de 2001, e as plantas foram conduzidas no sistema latada $(4,0 \times 1,5 \mathrm{~m})$, enxertadas sobre o porta-enxerto IAC 766 'Campinas'. As podas curtas de formação (duas gemas) foram realizadas no fim do mês de agosto de 2007 e 2008, e as podas longas de produção (oito gemas) foram realizadas no fim de fevereiro de 2008 e 2009. As avaliações foram realizadas em duas safras fora de época (2008 e 2009), a partir do início da maturação das uvas até sete dias após a colheita. Foram utilizadas 20 plantas representativas de cada variedade. Para a evolução da maturação fenólica das uvas, foi determinado o teor de antocianinas e o índice de polifenóis totais (IPT) do mosto das bagas. Por ocasião da colheita, foi avaliado o teor de resveratrol do mosto das uvas. Para a 'Alicante', a média do teor de antocianinas foi de 55,4 mg $100 \mathrm{~g}^{-1}$, IPT de $474,0 \mathrm{mg} 100 \mathrm{~g}^{-1}$ e teor de

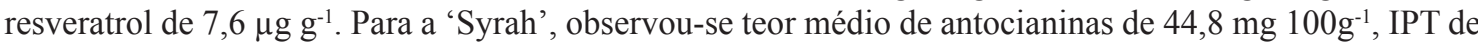
$487,7 \mathrm{mg} 100 \mathrm{~g}^{-1}$ e teor de resveratrol de $6,4 \mu \mathrm{g} \mathrm{g}^{-1}$. Considera-se que a evolução da maturação fenólica das uvas estudadas neste trabalho (progressiva para antocianinas e oscilatória para IPT) e o teor dos compostos fenólicos no momento da colheita são adequados para que estas sejam utilizadas como matéria-prima na elaboração de vinhos finos.

Termos para indexação: compostos fenólicos, poda, videira.

\section{PHENOLIC MATURATION EVOLUTION OF 'ALICANTE' AND 'SYRAH' GRAPES GROWN OUT OF SEASON}

\begin{abstract}
This study aimed to characterize the phenolic maturation of 'Alicante' and 'Syrah' grapes (Vitis vinifera L.) grown out of season. The experimental area was located in a property belonging to the Intervin ${ }^{\circledR}$ Winery, at Maringá, PR. The vineyards were established in July, 2001 and the vines were trained in an overhead trellising system $(4.0 \times 1.5 \mathrm{~m})$, grafted on IAC 766 'Campinas' rootstock. The spur pruning of formation (two buds) was held in late August of 2007 and 2008 and the long pruning of production (eight buds) was held in late February of 2008 and 2009. The evaluations were performed in two out of season grapes production (2008 and 2009), from early ripening up to seven days after harvest, using 20 representative vines of each variety. The grapes phenolic maturation evolution was determined by means of anthocyanins content and total polyphenols index (TPI) of the berries. During harvest, it was analyzed the resveratrol content of the must. The 'Alicante' showed an average content of anthocyanins of $55.4 \mathrm{mg}^{100 \mathrm{~g}^{-1}, 474.0}$ $\mathrm{mg} 100 \mathrm{~g}^{-1}$ of TPI and resveratrol content of $7.6 \mu \mathrm{g} \mathrm{g}{ }^{-1}$. For 'Syrah', the average content of anthocyanins

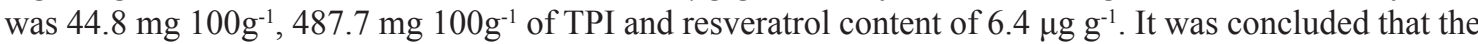
phenolic maturation evolution of grapes studied (progressive for anthocyanins and oscillatory for TPI) and the phenolic compounds at the harvest moment are appropriate for winemaking.
\end{abstract}

Index terms: phenolic compounds, pruning, vine.

\footnotetext{
${ }^{1}$ (Trabalho 136-11). Recebido em: 29-04-2011 . Aceito para publicação em: 29-02-12 . (Parte da Tese de Doutorado em Fitotecnia do primeiro autor, Universidade Estadual de Londrina).

${ }^{2}$ Eng. Agr., Dr., Universidade Estadual de Londrina, Caixa Postal 6001, 86051-990, Londrina, PR. E-mail: ajsato82@yahoo.com.br ${ }^{3}$ Eng. Agr., M. Sc., Universidade Estadual de Maringá, Av. Colombo, 5790, 87020-900. Maringá-PR. E-mails: c_lourenzi@hotmail. com; dalany5@hotmail.com; angelak.k@gmail.com

${ }^{4}$ Químico, Dr., Professor Associado, Departamento de Química. Universidade Estadual de Maringá, Bolsista do CNPq, Av. Colombo, 5790, 87020-900. Maringá-PR. E-mail: eclemente@uem.br

${ }_{5}^{5}$ Eng. Agr., Dr., Professor Associado, Departamento de Agronomia/Fitotecnia, Universidade Estadual de Londrina, Bolsista do CNPq, Caixa Postal 6001, 86051-990. E-mail: sroberto@uel.br .Autor para correspondência.
} 


\section{INTRODUÇÃO}

No Brasil, em função do crescente mercado consumidor de vinhos, cada vez mais competitivo, tem-se buscado desenvolver técnicas de cultivo que propiciem elevar a qualidade das uvas. Isso tem ocorrido em função das recentes divulgações sobre os efeitos benéficos dos vinhos à saúde, principalmente os tintos, em virtude da presença de compostos fenólicos e antioxidantes em sua composição (MELLO, 2007).

No Paraná, onde a viticultura é consolidada pela dupla safra anual de uvas finas de mesa, têm sido realizados grandes investimentos no cultivo de uvas para processamento, como a implantação da fábrica de sucos de uva da Cooperativa Corol, em Rolândia; a Vinícola Dezem, em Toledo; a Vinícola Intervin $^{\circledR}$, em Maringá, entre outros, impulsionados também pelo incentivo fiscal do governo estadual e pela busca de novos mercados consumidores (SATO; ROBERTO, 2008).

Entre as técnicas de cultivo utilizadas para a obtenção de uvas para processamento de qualidade superior, está a produção em safra fora de época, o que possibilita que a maturação das uvas ocorra em condições climáticas de menor precipitação e maior amplitude térmica, condições estas ideais para o desenvolvimento das mesmas (FAVERO et al., 2008). No entanto, essa técnica somente é possível devido às características climáticas das regiões subtropicais e ao uso da cianamida hidrogenada, que uniformiza a brotação e permite o desenvolvimento vegetativo das videiras durante todo o ano (KISHINO; CARAMORI, 2007).

Diversas são as cultivares destinadas à vinificação, entretanto algumas se destacam por se adaptarem muito bem às diversas regiões do mundo, como a 'Alicante' e a 'Syrah' (Vitis vinifera L.), ambas de origem francesa. A uva 'Alicante' é utilizada principalmente para agregar cor aos vinhos de variedades com coloração menos intensa, enquanto a 'Syrah' é utilizada tanto para a elaboração de vinhos varietais como para vinhos de corte (AMORIM et al., 2005).

Quando se deseja produzir uvas destinadas à vinificação em regiões onde seu cultivo é pouco conhecido, é importante que se avaliem suas características fenólicas, bem como sua evolução durante a maturação, pois a síntese e o acúmulo destes compostos nas uvas são influenciados diretamente pelas condições climáticas, tais como temperatura, intensidade luminosa e precipitação (BLOUIN; GUIMBERTEAU, 2004).

Com base nesses aspectos, este trabalho teve como objetivo caracterizar a evolução do comporta- mento da maturação fenólica das uvas 'Alicante' e 'Syrah' cultivadas fora de época.

\section{MATERIAL E MÉTODOS}

O trabalho foi conduzido em dois vinhedos experimentais das videiras 'Alicante' e 'Syrah' (Vitis vinifera L.), pertencentes à Vinícola Intervin ${ }^{\circledR}$, localizada em Maringá-PR $\left(23^{\circ} 25^{\prime} \mathrm{S}, 51^{\circ} 57^{\prime} \mathrm{W}\right.$, altitude de $542 \mathrm{~m}$ ). O clima da região é classificado de acordo com Köeppen como Cfa, ou seja, de clima subtropical com a temperatura média no mês mais frio inferior a $18^{\circ} \mathrm{C}$ e temperatura média do mês mais quente acima de $22^{\circ} \mathrm{C}$. A precipitação média anual é de $1.596 \mathrm{~mm}$, e a tendência é de concentração das chuvas nos meses de verão (IAPAR, 2010).

Foram utilizadas 20 plantas representativas de cada variedade (RIZZON; MIELE, 2002), conduzidas em sistema latada, em espaçamento de $4,0 \times 1,5 \mathrm{~m}$, e enxertadas em julho de 2001 sobre o porta-enxerto IAC 766 'Campinas'. As avaliações da evolução do comportamento das características fenólicas das uvas durante a maturação foram realizadas em duas safras fora de época consecutivas, em 2008 e 2009.

As podas curtas de formação (duas gemas) foram realizadas no fim de agosto de 2007 e 2008, e as podas longas de frutificação (oito gemas) foram realizadas no fim de fevereiro de 2008 e 2009, sendo que as folhas presentes nas varas antes da realização da poda foram removidas, e os cachos que porventura surgiram, eliminados, obtendo-se, desta forma, a colheita nos meses de junho e julho, ou seja, em período diferente das demais regiões brasileiras tradicionais no cultivo de uvas, em que geralmente a colheita é realizada entre dezembro e fevereiro.

A partir do início da maturação (meados de maio) até sete dias após a colheita (meados de agosto), foram coletadas semanalmente 60 bagas de cada planta, sendo estas retiradas da parte superior, mediana e basal dos cachos. As análises foram realizadas no Laboratório de Química da Universidade Estadual de Maringá-PR, quanto ao teor de antocianinas e índice de polifenóis totais (IPT) do mosto. Por ocasião da colheita, foram coletadas 10 bagas de cada planta (retiradas da parte superior, mediana e basal dos cachos) e analisadas quanto ao teor de resveratrol do mosto na Central de Análises Avançadas de Materiais da Universidade Estadual de Maringá.

Para a avaliação do teor de antocianinas das uvas, a extração foi realizada segundo a metodologia de Lee e Francis (1972), com algumas modificações: pesaram-se $50 \mathrm{~g}$ de cada amostra de uva, as quais foram trituradas durante dois minutos, 
com $50 \mathrm{~mL}$ da solução solvente de etanol a $70 \%$. Posteriormente, completou-se o volume para $200 \mathrm{~mL}$ e armazenou-se a solução coberta com parafilme, durante 12 horas, a $4^{\circ} \mathrm{C}$. O material foi filtrado em funil de Büchner, com auxílio de bomba de vácuo, retiraram-se $125 \mathrm{~mL}$ do filtrado e completou-se com o solvente para $250 \mathrm{~mL}$. Desta, retiraram-se amostras de $2 \mathrm{~mL}$ (em triplicata) e completou-se o volume para $100 \mathrm{~mL}$; em seguida, deixou-se por duas horas no escuro. A leitura foi realizada em espectrofotometro (modelo 6405, Jenway) a $535 \mathrm{~nm}$, usando como "branco" apenas o solvente.

Para o cálculo do teor de antocianinas, utilizou-se a seguinte fórmula (TEIXEIRA et al., 2008): Teor de antocianinas $\left(\mathrm{mg} 100 \mathrm{~g}^{-1}\right)=\left(\mathrm{Abs} . \mathrm{V}_{\mathrm{E} 1} \cdot \mathrm{V}_{\mathrm{E} 2}\right.$. 1.000) / ( $\mathrm{V}_{\mathrm{alq}} \cdot \mathrm{m}$. 982)

Em que:

Abs: Absorbância;

$\mathrm{V}_{\mathrm{E}}$ : Volume total do extrato filtrado $(250 \mathrm{~mL})$;

$\mathrm{V}_{\mathrm{E} 2}$ : Volume total do extrato diluído $(100 \mathrm{~mL})$;

$\mathrm{V}_{\text {alq }}$ : Alíquota da amostra filtrada a ser diluída $(2 \mathrm{~mL})$; $\mathrm{m}$ : massa da amostra de uvas (g).

A quantificação do índice de polifenóis totais (IPT) foi realizada baseada no método de Follin-Ciocauteau, de acordo com Bucic-Kojic et al. (2007). Pesou-se, aproximadamente, 2,5 g de bagas de cada amostra de uva, as quais foram trituradas com $50 \mathrm{~mL}$ de etanol a $50 \%$, durante dois minutos, e realizou-se a centrifugação (1.000 rpm) durante cinco minutos. Em seguida, retiraram-se amostras de 0,2 mL (em triplicata) desse extrato em tubo de ensaio, ao qual foram adicionados $1,8 \mathrm{~mL}$ de água destilada, $10 \mathrm{~mL}$ de solução de Follin-Ciocalteau a $10 \%$ e entre 30 segundos a oito minutos; adicionaram-se $8 \mathrm{~mL}$ de solução de carbonato de sódio $\left(\mathrm{Na}_{2} \mathrm{CO}_{3}\right)$ a $7,5 \%$. $\mathrm{O}$ tubo foi agitado e mantido no escuro por duas horas. Realizou-se a leitura em espectrofotômetro (modelo 6405, Jenway) a $765 \mathrm{~nm}$, usando como "branco" todos os reagentes sem a alíquota da amostra centrifugada, sendo adicionados dois $\mathrm{mL}$ de água destilada (completando-se 0,2 + 1,8 mL). $\mathrm{O}$ ácido gálico (GAE) foi usado como padrão, e a curva de calibração foi realizada com solução de GAE, nas concentrações de 0,$2 ; 0,4 ; 0,6 ; 0,8 ; 1,0$ e $1,2 \mu \mathrm{g} \mathrm{mg}^{-1}$. A partir desta, obteve-se por regressão linear a equação: $y=a x+b$, na qual a variável " $y$ " representa a absorbância, e, desta forma, obteve-se o valor do teor de composto fenólico em equivalente de ácido gálico.

Para o cálculo do IPT, utilizou-se a seguinte fórmula (BUCIC-KOJIC et al., 2007):

$$
\text { IPT }\left(\mathrm{mg} 100 \mathrm{~g}^{-1}\right)=\left(\mathrm{IPT}_{\mathrm{eq}} \text {. V) } .10\right.
$$

Em que:

$\mathrm{IPT}_{\text {eq }}$ : valor obtido na equação da curva de calibração;

V: Diluição da amostra (50 mL/massa da amostra).

Para a análise do teor de resveratrol das amostras, pesaram-se $50 \mathrm{~g}$ de uvas, as quais foram homogeneizadas durante um minuto com $50 \mathrm{~mL}$ da solução solvente de etanol a $80 \%$. As amostras trituradas foram dispostas em banho-maria por 30 minutos, em temperatura de $60^{\circ} \mathrm{C}$, e posteriormente permaneceram por 15 minutos na centrifugadora (1.000 rpm). O sobrenadante passou por filtro Millipore $0,22 \mu \mathrm{M}$, com auxílio de uma seringa.

As amostras filtradas em triplicata foram injetadas em Cromatógrafo Líquido de Alta Eficiência (CLAE) (modelo LC-10 VP, Shimadzu), e a coluna analítica utilizada foi a $\mathrm{C}_{18}$, de fase reversa (modelo CLC-ODS (M), Shim-pack), sendo a temperatura da coluna mantida a $40^{\circ} \mathrm{C}$

Para a eluição do resveratrol, foi utilizado o método por gradiente, com dois solventes para a fase móvel: solvente A (ácido acético glacial em água, pH 3,0$)$; solvente B (20\% do solvente A e $80 \%$ de acetonitrila), com vazão de $1,5 \mathrm{~mL} \mathrm{~min}^{-1}$, e injetor de $20 \mu \mathrm{L}$. A programação da fase móvel utilizada foi: tempo 0: $83,5 \%$ do solvente A e $16,5 \%$ do solvente B; aos 13 minutos: $82 \%$ do solvente A e $18 \%$ do solvente $\mathrm{B}$; aos 17 minutos: $77 \%$ do solvente A e $23 \%$ do solvente $\mathrm{B}$; aos 21 minutos: $75 \%$ do solvente A e $25 \%$ do solvente B; aos 27 minutos: $68,5 \%$ do solvente A e $31,5 \%$ do solvente $\mathrm{B}$; aos 30 minutos $0 \%$ do solvente A e $100 \%$ do solvente B (ROMEROPEREZ et al., 2001).

A quantificação do resveratrol foi obtida com base no tempo de retenção da amostra no cromatógrafo, em comparação com o padrão transresveratrol (Sigma R5010-100MG). Para o cálculo do teor deste composto, foi elaborada uma curva de calibração com diferentes concentrações do padrão Sigma $\left(1,3,5\right.$, 7 e $\left.9 \mu \mathrm{g} \mathrm{mg}^{-1}\right)$ e, por regressão linear, obteve-se a equação: $y=a x+b$, que foi utilizada para o cálculo do teor de resveratrol em $\mu \mathrm{g} \mathrm{g}^{-1}$, substituindo-se a variável " $\mathrm{x}$ " pela área do pico de resveratrol observada no CLAE.

Os dados climáticos da região, nos anos de 2008 e 2009 , como temperatura média mensal $\left({ }^{\circ} \mathrm{C}\right)$ e a precipitação pluviométrica total mensal $(\mathrm{mm})$ foram obtidos junto à Universidade Estadual de Maringá.

\section{RESULTADOS E DISCUSSÃO}

O comportamento do teor de antocianinas durante a maturação de ambas as uvas foi progres- 
sivo nas duas safras avaliadas (Figura 1). No início da maturação, a 'Alicante' apresentou teor de 5,9 mg $100 \mathrm{~g}^{-1}$ em 2008 e de $10,1 \mathrm{mg} 100 \mathrm{~g}^{-1}$ em 2009, sendo que, no momento da colheita, este teor foi de

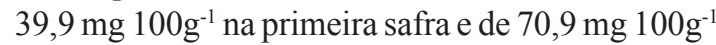
na segunda, com média geral de $55,4{\mathrm{mg} 100 \mathrm{~g}^{-1} \text { nas }}$ duas safras (Tabela 1). Para a 'Syrah', verificou-se teor inicial de antocianinas de $0,9 \mathrm{mg} 100 \mathrm{~g}^{-1}$ na safra

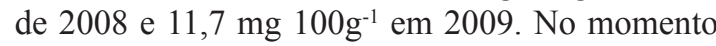
da colheita, este teor elevou-se para 40,1 e 49,5 mg $100 \mathrm{~g}^{-1}$, respectivamente, com média geral de 44,8 mg $100 \mathrm{~g}^{-1}$ (Tabela 1 ).

Assim como neste trabalho, Bevilaqua (1995), na Serra Gaúcha, verificou que a evolução do teor de antocianinas da videira 'Syrah' apresentou comportamento progressivo. No entanto, para as cultivares Pinot Noir e Merlot, o mesmo autor, na Serra Gaúcha, observou que o teor de antocianinas oscilou durante a maturação e que, no momento da colheita, o teor médio deste composto foi semelhante ao início da maturação.

A variação do teor de antocianinas das uvas 'Alicante' e 'Syrah', entre as safras de 2008 e 2009, está relacionada ao fato de a síntese deste composto ser influenciada diretamente pelas condições climáticas, como a temperatura, a intensidade luminosa e a precipitação (BEVILAQUA, 1995). De acordo com Lima (2009), a presença constante de intensidade luminosa estimula a síntese destes compostos; no entanto, sob temperaturas acima de $35^{\circ} \mathrm{C}$, sua síntese é inibida.

Abe et al. (2007) verificaram que o excesso de precipitação durante a safra regular inibe a síntese das antocianinas em diversas cultivares de uvas, assim como Favero (2007), que observou que a videira 'Syrah' cultivada em safra fora de época, no Sul de Minas Gerais, apresentou, no primeiro ano de pro-

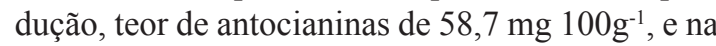

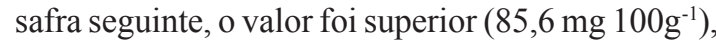
sendo que, no primeiro ano, a precipitação média no sul de Minas Gerais, durante a fase de maturação, foi cerca de $100 \mathrm{~mm}$ maior do que no segundo ano.

Os resultados obtidos no presente trabalho diferem do observado por Favero (2007), tendo em vista que, na área experimental, a precipitação média durante a fase final de maturação das uvas, na safra de 2008, foi menor em relação à de 2009 (44,6 e 120,8 mm, respectivamente), e o teor de antocianinas para ambas as uvas foi maior na safra de 2009 (Tabela 1). No entanto, deve-se considerar que a temperatura também influencia na síntese de antocianinas, de acordo com Champagnol (1984), as videiras submetidas a condições de temperaturas mais elevadas durante a fase de maturação tendem a reduzir a síntese deste composto, enquanto em condições de amplitude térmica mais elevada, sua síntese é favorecida.

Verificou-se, neste trabalho, que, durante a fase de maturação das uvas, a amplitude térmica foi semelhante nas duas safras avaliadas, no entanto a temperatura média diária e a temperatura máxima diária foram mais elevadas durante a safra de 2008 (temperatura média de $18,9^{\circ} \mathrm{C}$ em 2008 e $17,6^{\circ} \mathrm{C}$ em 2009 , e a temperatura máxima, em média, foi de $24^{\circ} \mathrm{C}$ em 2008 e de $22^{\circ} \mathrm{C}$ em 2009), o que corrobora Champagnol (1984) sobre a redução da síntese de antocianinas sob condições de cultivo em temperaturas mais elevadas.

Em relação ao IPT, houve grande variação durante a maturação das uvas, principalmente na safra de 2009 (Figura 1). No início da maturação, na safra de 2008, a 'Alicante' apresentou IPT de 419,4 $\mathrm{mg} 100 \mathrm{~g}^{-1}$. Durante essa fase, houve grande oscilação deste composto, o qual atingiu seu ápice na sexta se-

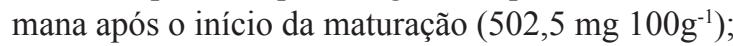
posteriormente, houve queda, atingindo no momento

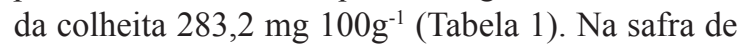
2009, observou-se o mesmo comportamento para essa uva, com teor inicial do IPT de 565,8 mg 100g${ }^{1}$. Na segunda semana após o início da maturação, a

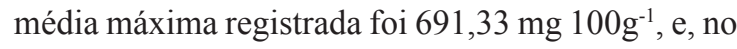

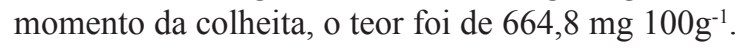
Dessa forma, a média do IPT, nas duas safras avaliadas, foi de 474,0 mg 100 $\mathrm{g}^{-1}$ (Tabela 1).

Para a 'Syrah', observa-se, na Figura 1, que na safra de 2008 o comportamento do IPT durante a maturação foi decrescente e, em 2009, houve variação no decorrer da maturação dessas uvas. No início da maturação da safra de 2008, o IPT foi de $556,8 \mathrm{mg}$ $100 \mathrm{~g}^{-1}$, e a partir dessa fase houve decréscimo até atingir o valor mínimo de $279,5 \mathrm{mg} 100 \mathrm{~g}^{-1}$ na quarta semana após o início da maturação. No momento da colheita, a média foi de $373,9 \mathrm{mg} 100 \mathrm{~g}^{-1}$ (Tabela 1). Na safra de 2009, o teor inicial do IPT foi de 584,5 mg $100 \mathrm{~g}^{-1}$, e o ápice ocorreu na segunda semana após

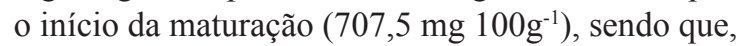
no momento da colheita, foi de $601,5 \mathrm{mg} 100 \mathrm{~g}^{-1}$. Portanto, a média do IPT para a 'Syrah', nas duas

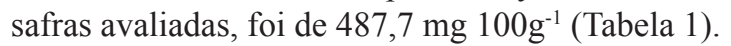

A oscilação do IPT durante a maturação das uvas também foi observada por Bevilaqua (1995), na Serra Gaúcha, para as cultivares Syrah, Cabernet Franc, Merlot, Pinot Noir e Gamay Beaujolais. De acordo com Ribéreau-Gayon e Stonestreet (1965), a redução no IPT logo após o início da maturação está relacionada ao fato de que, nesta fase, ocorre a polimerização dos taninos, que até então compunham grande parte dos compostos fenólicos totais, além do 
fato de que a maioria dos ácidos fenólicos passam a se degradar no decorrer da maturação das uvas.

A degradação dos ácidos fenólicos, bem como a polimerização dos taninos, é influenciada diretamente pelas condições climáticas, como a temperatura e a precipitação (RIBÉREAUGAYON;STONESTREET, 1965). No presente trabalho, verificou-se que, durante a fase de maturação das uvas 'Alicante' e 'Syrah', a temperatura média diária e a temperatura máxima diária foram mais elevadas na safra de 2008 (temperatura média de $18,9^{\circ} \mathrm{C}$ em 2008 e $17,6^{\circ} \mathrm{C}$ em 2009 , e temperatura máxima em média de $24^{\circ} \mathrm{C}$ em 2008 e de $22^{\circ} \mathrm{C}$ em 2009), bem como a precipitação durante a maturação na safra de 2008 foi mais elevada (179mm em 2008 e 85 mm em 2009), o que pode ter influenciado na degradação dos ácidos fenólicos na primeira safra, e desta forma o IPT ter sido mais elevado na segunda safra.

Devido ao fato de o IPT oscilar durante a fase de maturação, quando se buscam uvas destinadas à elaboração de vinhos, deve-se considerar este índice, principalmente na fase final de maturação, ou seja, no período próximo à colheita, tendo em vista que é essencial conhecer o teor de polifenóis e de antocianinas das uvas no momento em que estas serão utilizadas na elaboração dos vinhos, e desta forma, definir as técnicas de vinificação mais adequadas, de acordo com a matéria-prima disponível.

São raras as informações sobre o IPT nas bagas das uvas, pois a maioria dos trabalhos realizados está baseada na quantificação destes compostos nos vinhos. Entretanto, verifica-se que as médias aqui obtidas estão acima das obtidas por Abe et al. (2007), que encontraram para a 'Syrah', cultivada em Minas Gerais, IPT de 385 mg $100 \mathrm{~g}^{-1}$. Os mesmos autores relatam que a cultivar Merlot apresenta teor de 337 mg $100 \mathrm{~g}^{-1}$, ou seja, resultados abaixo ao obtido para a 'Alicante' e a 'Syrah', neste trabalho.

Em relação à concentração de resveratrol, observa-se na Tabela 1 que a 'Alicante' e a 'Syrah' apresentaram em média, 7,6 e 6,4 $\mu \mathrm{g} \mathrm{g}^{-1}$, respectivamente. Para este composto, não ocorreram grandes variações entre as safras avaliadas (2008 e 2009), sendo que, para a 'Alicante', as médias foram de 6,7 e 8,6 $\mu \mathrm{g} \mathrm{g}^{-1}$, respectivamente, e para a 'Syrah', foram de 6,5 e $6,3 \mu \mathrm{g} \mathrm{g}^{-1}$, respectivamente.

Assim como ocorre para o IPT, as informações acerca do teor de resveratrol no mosto das uvas são bastante raras. No entanto, constatou-se que os resultados da 'Syrah' são semelhantes aos encontrados por Abe et al. (2007), que verificaram em Minas Gerais teor de $6,0 \mu \mathrm{g} \mathrm{g}^{-1}$ para esta mesma uva e 5,0 $\mu \mathrm{g}$ $\mathrm{g}^{-1}$ para a 'Merlot'. O resveratrol é um dos compostos fenólicos mais desejados nos vinhos tintos, devido aos efeitos benéficos à saúde propiciados pelo seu consumo (RIBEIRO; MANFROI, 2010). Portanto, a quantificação de seu teor, nas uvas, é fundamental para que os métodos de elaboração dos vinhos sejam definidos, uma vez que, assim como ocorre para as antocianinas, o acúmulo deste composto ocorre na casca das bagas (PRICE et al., 1995). Desta forma, a presença do resveratrol nos vinhos dependerá não só das características das uvas utilizadas, bem como das técnicas de extração utilizadas na vinificação.

TABELA 1 - Características dos compostos fenólicos do mosto das bagas das videiras 'Alicante' e 'Syrah', produzidas fora de época, nas safras de 2008 e 2009. Maringá, PR.

\begin{tabular}{|c|c|c|c|}
\hline \multirow{2}{*}{ Variáveis } & \multicolumn{3}{|c|}{ 'Alicante' } \\
\hline & Safra 2008 & Safra 2009 & Média \\
\hline Antocianinas (mg 100 $\left.\mathrm{g}^{-1}\right)$ & $39,9 \pm 1,1$ & $70,9 \pm 4,3$ & $55,4 \pm 21,9$ \\
\hline $\mathrm{IPT}^{\mathrm{a} /}\left(\mathrm{mg} \mathrm{100 \textrm {g } ^ { - 1 } )}\right.$ & $283,2 \pm 142,0$ & $664,8 \pm 74,0$ & $474,0 \pm 269,8$ \\
\hline \multirow[t]{2}{*}{ Resveratrol $\left(\mu \mathrm{g} \mathrm{g}^{-1}\right)$} & $6,7 \pm 1,4$ & $8,6 \pm 0,4$ & $7,6 \pm 1,3$ \\
\hline & & 'Syrah' & \\
\hline Antocianinas (mg $\left.100 \mathrm{~g}^{-1}\right)$ & $40,1 \pm 0,2$ & $49,5 \pm 4,3$ & $44,8 \pm 6,6$ \\
\hline $\mathrm{IPT}^{\mathrm{a} /}\left(\mathrm{mg} 100 \mathrm{~g}^{-1}\right)$ & $373,9 \pm 85,0$ & $601,5 \pm 74,0$ & $487,7 \pm 160,9$ \\
\hline Resveratrol $\left(\mu \mathrm{g} \mathrm{g}^{-1}\right)$ & $6,5 \pm 0,9$ & $6,3 \pm 0,4$ & $6,4 \pm 0,1$ \\
\hline
\end{tabular}

a: Índice de polifenóis totais. 

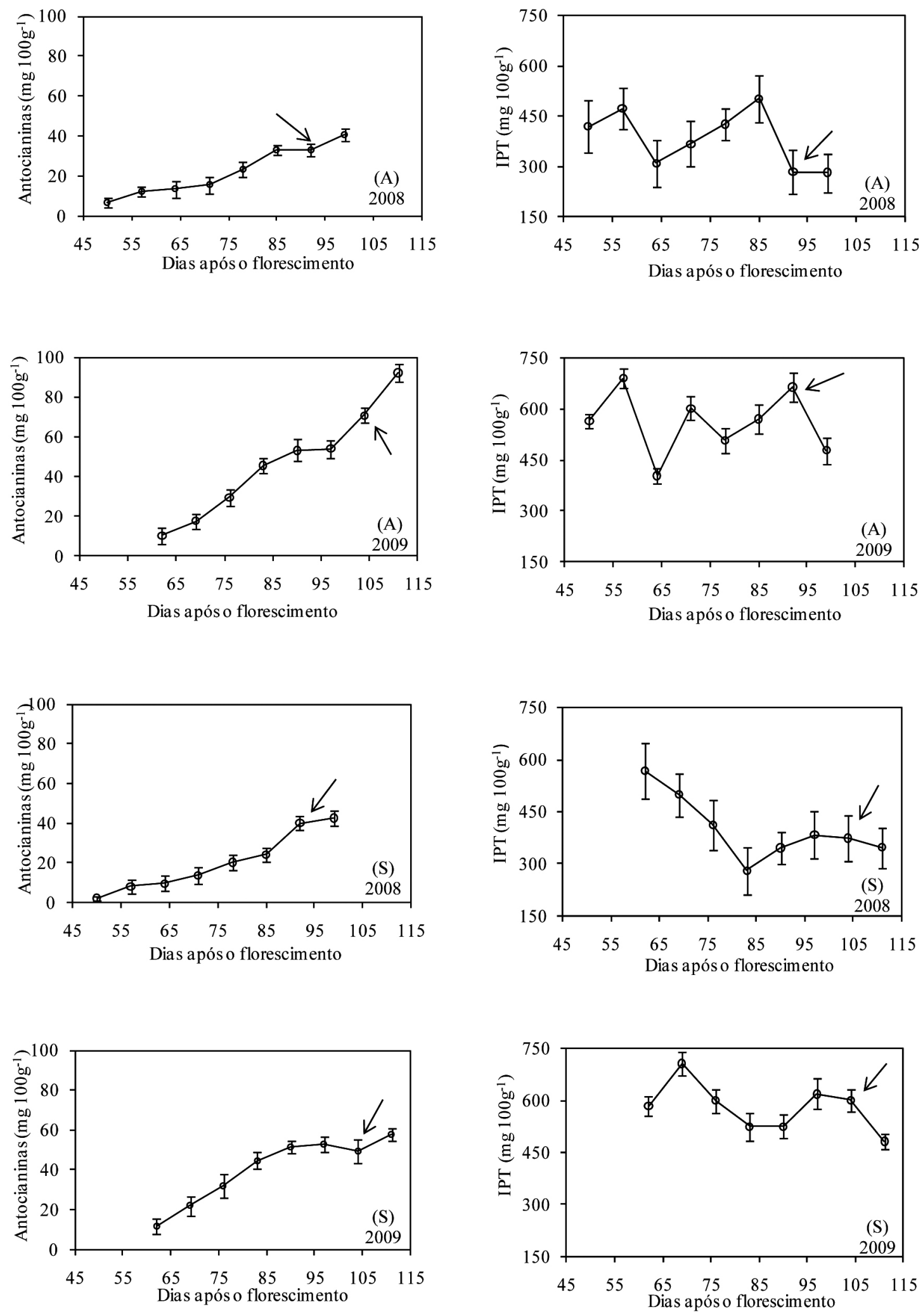

FIGURA 1 - Evolução do teor de antocianinas e do índice de polifenóis totais (IPT) do mosto da uva 'Alicante' (A) e 'Syrah' (S), produzidas fora de época, nas safras de 2008 e 2009. Maringá-PR. Obs: As setas indicam o momento da colheita, e as barras verticais, o desvio-padrão. 


\section{CONCLUSÕES}

De acordo com os resultados obtidos neste trabalho, verifica-se que a evolução da maturação fenólica das uvas ‘Alicante' e 'Syrah', cultivadas em safra fora de época, bem como o teor dos compostos fenólicos no momento da colheita são adequados para que essas uvas sejam utilizadas como matéria-prima na elaboração de vinhos finos.

\section{REFERÊNCIAS}

ABE, L. T.; DA MOTA, R. V.; LAJOLO, F. M.; GENOVESE, M. I. Compostos fenólicos e capacidade antioxidante de cultivares de uvas Vitis labrusca L. e Vitis vinifera L. Ciência e Tecnologia de Alimentos, Campinas, v.27, n.2, p.394-400, 2007.

AMORIM, D.A.; FAVERO, A.C.; REGINA, M.A. Produção extemporânea da videira, cultivar Syrah, nas condições do sul de Minas Gerais. Revista Brasileira de Fruticultura, Jaboticabal, v. 27, n. 2, p. 327-331, 2005.

BEVILAQUA, B. A. P. Avaliações físico-químicas durante a maturação de videiras cultivadas no Rio Grande do Sul. Revista Brasileira de Agrociência, Pelotas, v.1, n.3, p.151-156, 1995.

BLOUIN, J.; GUIMBERTEAU, G. Maduracion y madurez de la uva. Madrid: Ediciones MundiPrensa, 2004. 151p.

BUCIC-KOJIC, A.; PLANINIC, M.; TOMAS, S.; BILIC, M.; VELIC, D. Study of solid-liquid extraction kinetics of total polyphenols from grapes seeds. Journal of Food Engineering, Davis, v.81, n.1, p.236-242, 2007.

CHAMPAGNOL, F. Elements de physiologie de la vigne et de viticulture generale. Saint-Gely-duFesc: Champagnol, 1984. 351p.

FAVERO, A. C. Viabilidade de produção da videira 'Syrah' em ciclos de verão e inverno no sul de Minas Gerais. 2007. 124f. Dissertação (Mestrado em Agronomia). Universidade Federal de Lavras, Lavras, 2007.
FAVERO, A. C.; AMORIM, D. A.; MOTA, R. V.; SOARES, A. M.; REGINA, M. A. Viabilidade de produção da videira 'Syrah', em ciclo de outono inverno, no sul de Minas Gerais. Revista Brasileira de Fruticultura, Jaboticabal, v.30, n.3, p.685-690, 2008 .

INSTITUTO AGRONÔMICO DO PARANÁ - IAPAR. Carta climáticas do Paraná. Versão eletrônica, 2010. Disponível em: < http://www.iapar.br/ modules/conteudo/conteudo.php? conteudo $=677>$. Acesso em: 20 out. 2010.

KISHINO, A. Y.; CARAMORI, P. H. Fatores Climáticos e o Desenvolvimento da Videira. In: KISHINO, A. Y.; CARVALHO, S. L. C. de.; ROBERTO, S. R. Viticultura tropical: o sistema de produção do Paraná. Londrina: Iapar, 2007. p.59-86.

LEE, D. H.; FRANCIS, F. J. Standardization of pigment analyses in cranberries. HortScience, Stanford, v.7, n. 1, p.83-84, 1972.

LIMA, M. A. C. Fisiologia, tecnologia e manejo pós-colheita. In: SOARES, J. M.; LEÃO, P. C. S. A Vitivinicultura no semiárido brasileiro. Brasília: Embrapa Informação Tecnológica; Petrolina: Embrapa Semiárido, 2009. p.599-656.

MELLO, L. M. R. Panorama: anuário brasileiro da uva e do vinho. Santa Cruz do Sul: Gazeta, 2007. p.34-40.

PRICE, S. F.; BREEN, P. J.; VALLADAO, M.; WATSON, B. T. Cluster sun exposure and quercetin in Pinot noir grapes and wine. American Journal of Enology and Viticulture, Davis, v.46, n.1, p.187194, 1995

RIBEIRO, M. E. M.; MANFROI, V. Vinho e Saúde: uma visão química. Revista Brasileira de Viticultura e Enologia, Bento Gonçalves, v.1, n.2, p.91-103, 2010.

RIBÉREAU-GAYON, P.; STONESTREET, E. Le dosage des anthocyanes dans les vins rouges. Bulletin de la Societé Chimique de France, Paris, v.9, n.419, p.2.649-2.652, 1965.

RIZZON, L. A.; MIELE, A. Avaliação da cv. Cabernet Sauvignon para elaboração de vinho tinto. Ciência e Tecnologia de Alimentos, Campinas, v.22, n.2, p.156-161, 2002. 
ROMERO-PEREZ, A. R.; LAMUELA, R. C.; ANDRES, L.; BONAT, T. Method for the quantitative extraction of resveratrol and piceid isomers in grape berry skins. Effect of powdery mildew on the stilbene content. Journal of Agricultural and Food Chemistry, Davis, v.49, n.1, p.210-215, 2001.

SATO, A. J.; ROBERTO, S. R. Tecnologia de produção de uvas rústicas para mesa e processamento no norte do Paraná. In: BOLIANI, A. C.; FRACARO, A. A.; CORRÊA, L. S. Uvas rústicas de mesa: cultivo e processamento em regiões tropicais. Jales: [s.n], 2008. p.275-302.
TEIXEIRA, L. N.; STRINGHETA, P. C.; OLIVEIRA, F. A. Comparação de métodos para quantificação de antocianinas. Revista Ceres, Viçosa, MG, v.55, n.4, p.297-304, 2008. 